\title{
Perspectives on ecological risks of microplastics and phthalate acid esters in crop production systems
}

\author{
Fang Wang ${ }^{1,2, *}$, Yu Wang ${ }^{1,2}$, Leilei Xiang ${ }^{1,2}$, Marc Redmile-Gordon ${ }^{4}$, Chenggang Gu $^{1,2}$, Xinglun Yang ${ }^{1,2}$, \\ Xin Jiang ${ }^{1,2}$, Damià Barceló ${ }^{3}$ \\ 1 CAS Key Laboratory of Soil Environment and Pollution Remediation, Institute of Soil Science, Chinese Academy of Sciences, Nanjing \\ 210008, China \\ 2 University of Chinese Academy of Sciences, Beijing 100049, China \\ 3 Catalan Institute for Water Research, Girona, Spain \\ 4 Department of Environmental Horticulture, Royal Horticultural Society, Wisley, Surrey, GU23 6QB, UK
}

\section{H I G H L I G H T S}

- Microplastics and phthalate acid esters concentrations are positively correlated in soils.

- Phthalate acid esters levels are greatest in Chinese soils.

- Microplastics and phthalate acid esters share common sources and sinks.

- Microplastics and phthalate acid esters are taken up by plants.

- Microplastics and phthalate acid esters exert confounded influences on soil ecosystems.

\section{ARTICLE INFO}

Article history:

Received December 31, 2020

Revised April 6, 2021

Accepted April 17, 2021

Keywords:

Soil contaminant co-behavior

Microplastic-resident plasticizers

Phthalate acid esters (PAEs)

Microplastics

Transfer

Ecotoxicity
GRAPHICAL ABSTRACT

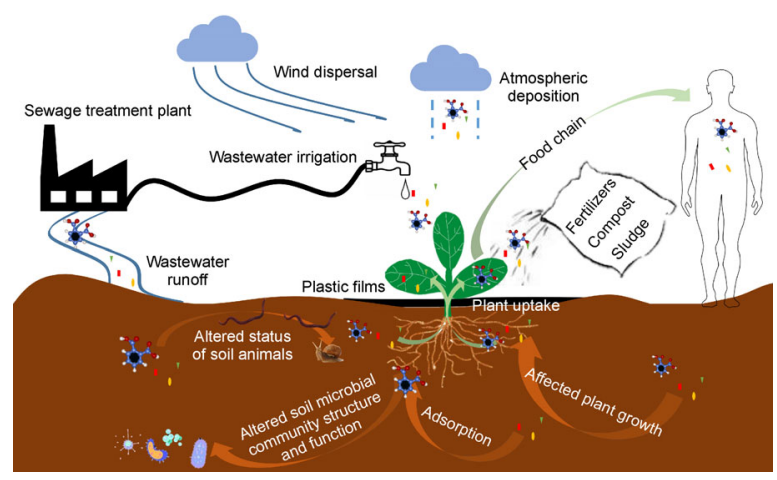

A B S T R A C T

Microplastics (MPs) and phthalate acid esters (PAEs) co-occur as emerging contaminants of global importance. Their abundance in soil is of increasing concern as plastic-intensive practices continue. Mulching with plastic films, inclusion in fertilizers, composts, sludge application, and wastewater irrigation are all major and common sources of MPs and PAEs in soil. Here, we review studies on the concentration and effects of MPs and PAEs in soil. While there is limited research on the interactions between MPs and PAEs in agroecosystems, there is evidence to suggest they could mutually affect soil ecology and plant growth. Therefore, we propose new research into 1) establishing an efficient, accurate, and simple method to quantify different types of microplastics in soils and plants; 2) exploring the behavior and understanding the mechanisms of co-transfer, transformation, and interactions with soil biota (especially in vegetable production systems); 3 ) assessing the risk and consequences of combined and discreet impacts of MPs and PAEs on plants and soil biota, and 4) preventing or reducing the transfer of MPs and PAEs into- and within- the food chain.

(c) Higher Education Press 2021

* Corresponding author

E-mail address: fangwang321@issas.ac.cn, wangfang@issas.ac.cn (F. Wang) 


\section{Introduction}

As a result of wide application of plastics, both microplastics (MPs) and phthalate acid esters (PAEs) are emerging as troublesome environmental contaminants. PAEs are commonly included in plastics owing to their function as 'plasticizers' (Staples et al., 1997), while MPs are defined by their plastic material particle size being less than $5 \mathrm{~mm}(\mathrm{Qi}$ et al., 2020). As PAEs are not covalently bonded with plastic polymers, there is potential for leaching, migration, and subsequently enhanced abrasion of the plastics containing them (Steinmetz et al., 2016). Accordingly, plastics abrade into progressively smaller particles, including MPs and nanoplastics (NPs) (Duis and Coors, 2016). PAEs and MPs share some common origins as 'partners' in plastic polymers used in horticulture and farming. Some of these products are clearly visible on farmlands (plastic films, nets, green packaging from agronomic products, and shredded compost contamination), but there are invisible sources, for example, fragments from fertilizers or colloidal suspensions in irrigation. Nonetheless, the soil receives both the obvious and more ambiguous inputs: being the common sink for both MPs and PAEs.

PAEs (Gu et al., 2017) and MPs (Lv et al., 2018; Qi et al., 2020) have been widely studied as separate contaminants in farmland soil. However, the PAE content of MPs is often not reported, and the affinity and interactions between MPs and PAEs in the soil have become a subject that cannot be ignored. A more comprehensive understanding requires us to elucidate the separate effects of MPs and the PAEs they contain. Some have monitored the effect of MPs on PAE migration (Gao et al., 2019; Li et al., 2020). However, as MPs are also a source of PAEs, it is necessary to study the interacting 'co-behaviors' to be able to more confidently allocate ecological risks of MPs and associated PAEs in soil. The present review focuses on the recent progress in characterizing this pollution, behavior, and the entwined ecological effects of PAEs and MPs in soil.

\section{Occurrence and distribution of PAEs and MPs in soil}

In recent decades, the PAE concentration of agricultural soil had been widely investigated (Fig. 1). The average concentrations of PAEs in the agricultural soil in China were higher than those elsewhere (Table 1). Di(2-Ethylhexyl)Phthalate (DEHP) was the most abundant phthalate in all soils, whereas di-butyl phthalate (DBP) was the second most abundant ( $\mathrm{Hu}$ et al., 2003). There is currently no standard approach for the quantification of plastics in soil, with the separation of MPs from soils being the most difficult and most crucial step. At present, the separation methods include screening, density separation, pressurized fluid extraction, and digestion $(\mathrm{He}$ et al., 2018). Methods for the extraction of polypropylene microplastics in swine manure have also been proposed $(\mathrm{Wu}$ et al., 2020). The main qualitative means of analyzing MPs is attenuated total reflection-Fourier transform infrared spectroscopy (Weithmann et al., 2018). Due to the emerging concern of MPs in aquatic systems, coastal beach sediments in many coastal areas have been well studied. Although the occurrence of MPs in terrestrial ecosystems has been repeatedly reported, there are significant knowledge gaps. In agricultural soils, MPs with sizes less than $0.5 \mathrm{~mm}$ are the most abundant (Table 2). However, it is also difficult to quantify MPs of much smaller size, especially nanoplastics (NPs) with a size range of 1 to $100 \mathrm{~nm}$.

Environmental concentrations of PAEs and abundances of MPs are closely linked, as found in surface seawater from Jiaozhou Bay (Liu et al., 2020b), coastal psammitic sediments in the tropical Atlantic Ocean (Benson and Fred-Ahmadu, 2020), north China (Zhang et al., 2018), and the urban channel of the Ria and coast of Campeche in Mexico (Vered et al., 2019). The concentration of DEHP increased with the abundance of MPs in wastewater $\left(R^{2}=0.97, P<0.05\right)$ (Takdastan et al., 2021). PAEs in the MPs from sandy beaches of tropical Atlantic ecosystems in Nigeria measured up to $45.6 \mathrm{mg}$ DEHP kg$^{-1}$ plastic (Fred-Ahmadu et al., 2020). PAEs in plastics were even used as tracers to determine the sources of MPs in road dust (Kitahara and Nakata, 2020). However, Li et al. (2021) suggested that environmental factors must be considered to understand the genuinely dynamic relationship between PAEs and MPs in agricultural soil. While MP concentrations depend mainly on input levels, PAE concentrations in soil are more influenced by degradation and dispersal.

\section{Sources of PAEs and MPs in soil}

There are many shared routes through which PAEs and MPs can enter the soil environment, especially for agricultural soils, including plastic mulching, soil amendment with fertilizers, contaminated composts and sewage sludge, irrigation, and atmospheric deposition. In the agricultural context, plastic film was considered the main source of PAEs (Lv et al., 2018) and MPs (Zhou et al., 2020b), followed by fertilizers, composts, and sludges. In gardens and domestic food production, organic fertilizers from biowaste fermentation (anaerobic digestate) and composting are a significant but often overlooked source of microplastics (Weithmann et al., 2018). Irrigation is an essential source of PAEs (Zhang et al., 2015b) and MPs (Ding et al., 2021) for soil in wastewater irrigation areas. Atmospheric deposition introduces both PAEs (Zeng et al., 2010) and MPs (Zhang et al., 2019d) into remote areas.

\subsection{Plastic film}

Plastic films have been used to mulch soil in recent decades worldwide, bringing significant short-term economic benefits. 


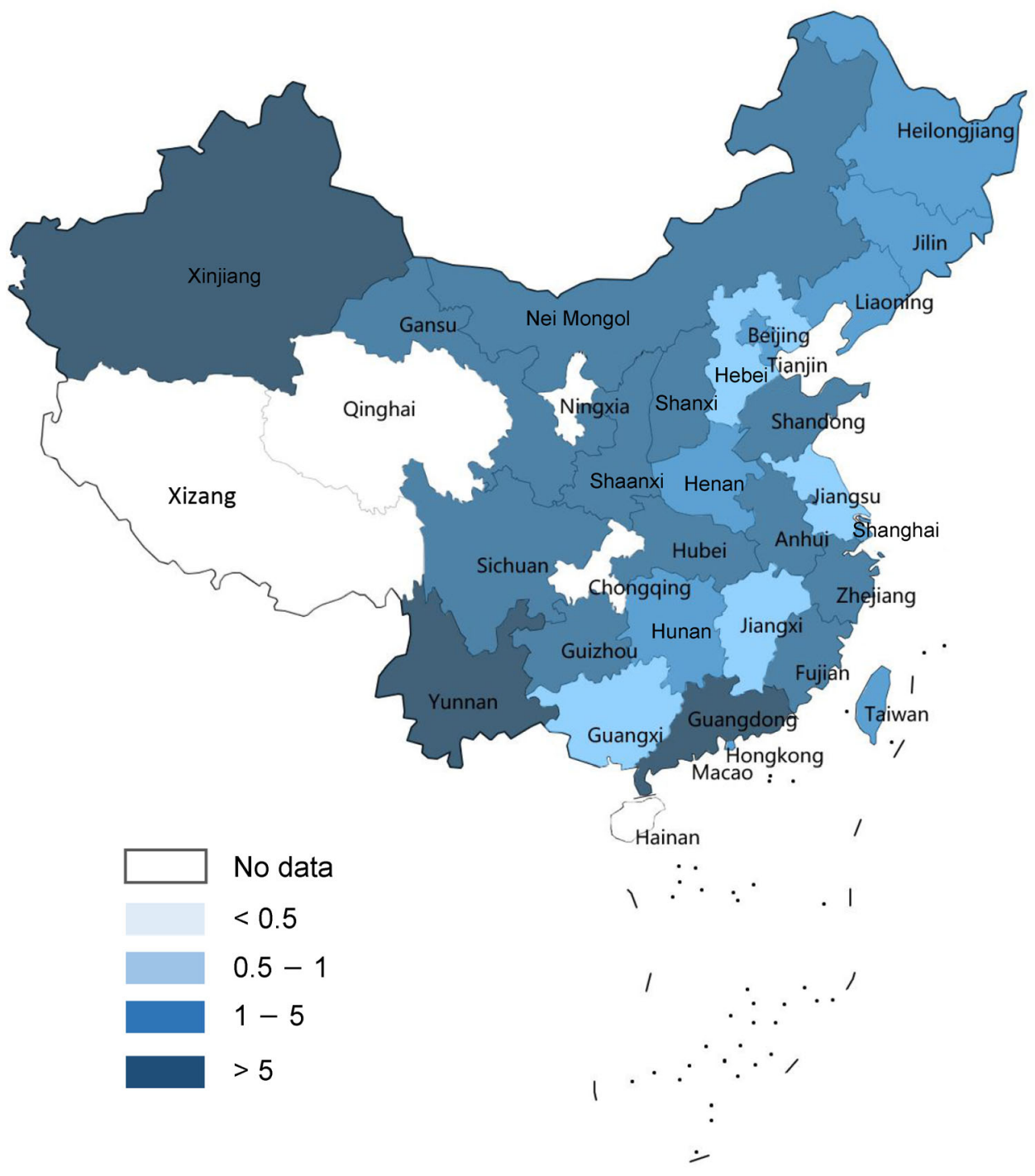

Fig. 1 Average concentrations of phthalate acid esters (PAEs) in soil in provinces in China .

With the extensive use of plastic mulch, PAEs can migrate directly from films to the soil, but substantial amounts of PAEs are found resident in discarded plastic residues incorporated into the soil, which progressively abrade to MPs and NPs. The average residual rate of plastic mulch was $19.7 \%$ following the bulletin of the first national census on pollution sources in China (Lv et al., 2018). Such intensive application and poor disposal of plastic mulch are essential contributors for MPs in terrestrial environments (Table 2). A significant linear correlation was observed between the amount of film mulching and plastic residue in soils (Zhou et al., 2020a). Meanwhile, there was a positive correlation between MPs and PAEs in the greenhouse soil in Xuzhou, China (Li et al., 2021). Timely recovery of plastic film waste is the most efficient (medium to long-term) and effective way to reduce the pollution burden of MPs and PAEs in soil.

\subsection{Fertilisers, compost, and sludge}

The use of organic fertilizers, compost, and sludge in plant production systems (Lowman et al., 2013) is central to maintaining nutrient-use efficiency and soil health through carbon metabolism and ecology of the soil microbiome (Kibblewhite et al., 2008). However, some fertilizers were found to contain quantities of PAEs ranging from 0.01 to 2.8 $\mathrm{mg} \mathrm{kg}^{-1}$ (Mo et al., 2008), presumably as PAEs leached from plastic packaging. A positive correlation was observed between zfertilizer application rate and PAE content in the soils of Guangdong's greenhouses (Cai et al., 2005; Cai et al., 2008a). The application of composted manure adds extraneous dissolved organic matter (DOM) to the soil, and DOM enhances the adsorption capacity of DBP by soils through partitioning (Wu et al., 2018). Organic fertilizers, manures, composts, and biowaste fermentation (anaerobic digestate) 
Table 1 Average concentrations of phthalate acid esters (PAEs) in soil in China and other countries $\left(\mathrm{mg} \mathrm{kg}^{-1}\right)$.

\begin{tabular}{|c|c|c|c|c|c|}
\hline \multirow[t]{2}{*}{ Country } & \multirow[t]{2}{*}{ Soil type } & \multicolumn{3}{|c|}{ PAE concentration $\left(\mathrm{mg} \mathrm{kg}^{-1}\right)$} & \multirow[t]{2}{*}{ Reference } \\
\hline & & Min & Max & Mean & \\
\hline China & Agricultural & 0.032 & 6.29 & 1.09 & Niu et al., 2014 \\
\hline Denmark & Agricultural & 0.012 & 1.9 & 0.39 & Vikelsoe et al., 2002 \\
\hline Scotland & Surface & 0.025 & 1.6 & 0.22 & Rhind et al., 2013 \\
\hline Netherlands & Agricultural & ND & - & 0.032 & Peijnenburg et al., 2006 \\
\hline Serbia & Surface & 0.19 & 2.12 & 0.83 & Skrbic et al., 2016 \\
\hline UK & Agricultural & 0.042 & 0.099 & 0.071 & Gibson et al., 2005 \\
\hline Czech Republic & Agricultural & 0.21 & 3.47 & - & Dankova et al., 2016 \\
\hline
\end{tabular}

"-" means no data.

are all known sources of MPs and PAEs in the environment; 16 PAEs were identified in sludge from Shanghai ranging from 22.6 to $1350 \mathrm{mg} \mathrm{PAEs} \mathrm{kg}^{-1}$ sludge (dry weight) (Zhao et al., 2014). MP content was up to 41 particles $\mathrm{g}^{-1}$ in sludge from fields that underwent sludge applications (Corradini et al., 2019). Braun et al. (2021) estimated that typical compost applications drew in plastic loadings of between 84000 to 1610000 plastic items ha ${ }^{-1}$ per year, equivalent to 0.34 to $47.53 \mathrm{~kg}$ plastic. Sludge tends to be destined as a soil amendment in most countries (Gao et al., 2020a). Investigations of MPs in sludge amended soils showed a close correlation to the application rate of sludge-based fertilizers (Zhang et al., 2020). Limits and standards for MP and PAE inputs from fertilizers, composts, and sludges will be central to controlling and managing this growing issue.

\subsection{Wastewater irrigation}

With shortages in water resources, wastewater and reclaimed water have been widely used to support agricultural production, especially in areas around industrial cities (Hamilton et al., 2007). Six priority PAEs were found to be ubiquitous environmental contaminants in topsoil obtained from such areas (Zhang et al., 2015b). The amount of treated wastewater used for irrigation is increasing worldwide (Sato et al., 2013). The abundance of MPs in water was up to 9.0 items $L^{-1}$ in the Al-Asfar and Al-Hubail lake (Picó et al., 2020), with the abundance of MPs in soil being affected by the type of irrigation water (Wang et al., 2020b). During wastewater treatments, the addition of polymeric flocculants has been considered a potential source (Hurley and Nizzetto, 2018).

\subsection{Atmospheric deposition}

Atmospheric PAE deposition and particulate deposition fluxes were closely related in the subtropical city of Guangzhou, China (Zeng et al., 2010). Atmospheric transport is also an essential pathway for the transport of MPs from industrial to remote areas (Zhang et al., 2019d). In the Pyrenean
Mountains, deposition of MPs was attributed to cities, agricultural, and industrial areas (Zhang et al., 2019d). Thus PAEs in the soil and atmosphere are distributed, migrate, redistribute, and remigrate toward equilibrium ( $\mathrm{Gu}$ et al., 2017).

To more accurately describe the movement and impacts of both classes of contaminants in the environment requires an understanding of the affinity between them, i.e., the factors determining their partnership and departure from one another. While, for the most part, MPs as physical particles can be seen to move unaffected by their PAE content, there are some exceptions where the PAE content may affect the movement of MPs. This is because PAEs modify the physical properties of a plastic, for example, improving 'plasticity' or resilience against abrasion. Therefore, the PAE content (related to age) may well affect the abrasion and shedding of these MPs into the environment. Perhaps the best example can be found in plastic recreational surfaces. Plastic grass or 'artificial lawns' are an increasingly popular way of simulating a lush ecosystem in gardens and sports venues (Francis, 2018), but the environmental impacts of abraded dust from cleaning and wear are still not well understood (Francis, 2018). Artificial lawns can include PA, or PE-based materials, sewn into an expanded polypropylene mesh, sometimes combined with butyl rubber or latex linings, and were previously found to host a range of plasticizers and PAEs (Celeiro et al., 2018). Over time, these finely woven plastics are increasingly vulnerable to physical wear under foot traffic, resulting in the release of MPs and their associated PAEs into the atmosphere. While initially resilient, we expect the abrasion of these surfaces to accelerate as plasticizers are lost from the matrix.

\section{Behavior of PAEs and MPs in soil}

The behavior of PAEs in the soil is reasonably well documented. For example, Wu et al. (2018) found that the equilibrium adsorption quantity for DBP was positively related to the soil organic matter content, and hydrophobic partition- 


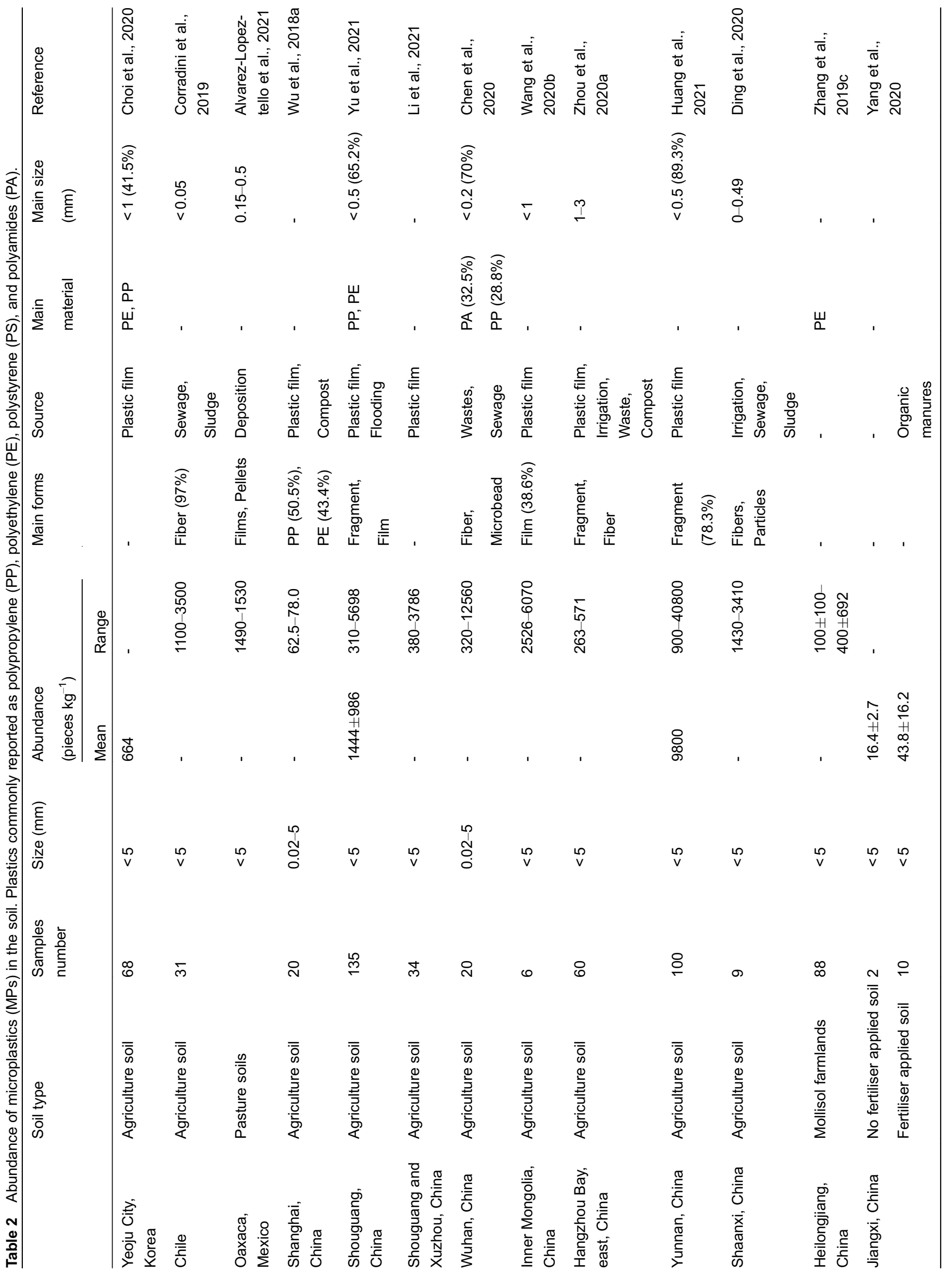




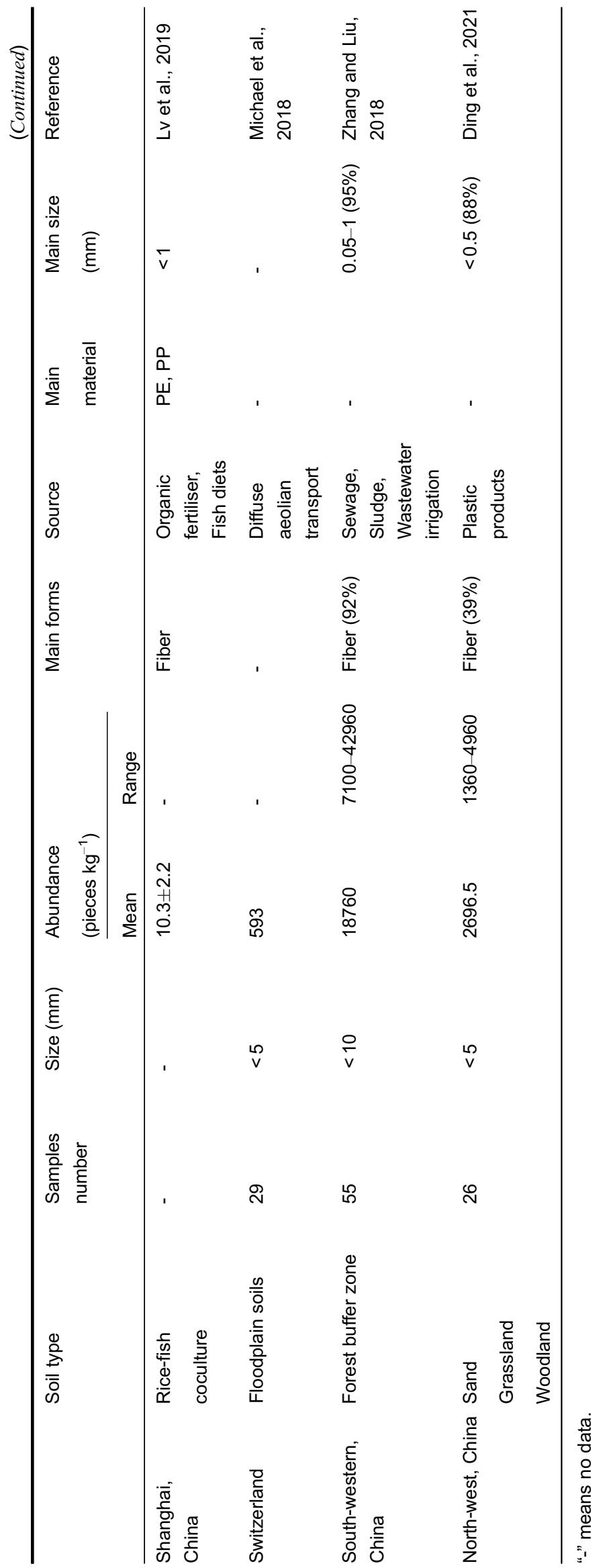


ing played a dominant role in the DBP adsorption process. However, the interaction effects of MP identity and MP particle size on the adsorption of PAEs are still unknown. While PAEs can be dispersed into the environment independently of MPs, the movement of MPs and PAEs through the environment are coupled in several ways, as they share an affinity for one another. The first aspect of this affinity is the straightforward inclusion of PAEs during the manufacture of the original plastics and subsequent dispersal of the PAEs contained within as microplastics shed and abrade into the environment: in this respect, MPs function as a source of PAEs. However, the second aspect of this affinity operates in the reverse direction, where PAEs are adsorbed by microplastics.

\subsection{Adsorption of PAEs on MPs}

Due to their small size and large specific surface area, MPs are capable of adsorbing large quantities of persistent organic pollutants (POPs) (Rios et al., 2007), including PAEs. Different adsorption mechanisms exist between organic pollutants and microplastics, depending on the chemistry of MP and PAE, respectively. In aqueous ecosystems, the sorption isotherms of diethyl phthalate (DEP) and di-butyl phthalate (DBP) on MPs (PS, PVC, PE) were highly linear. The higher adsorption rates for DBP relative to DEP and greater hydrophobicity of DBP again suggested that hydrophobic interactions are of major importance (Liu et al., 2019). Here, the solution pH and natural organic matter content had no significant impact on the adsorption of PAEs to MPs. However, due to the presence of the salting-out effect, the adsorption of PAEs on MPs was enhanced by $\mathrm{NaCl}$ and $\mathrm{CaCl}_{2}$ (Zhang et al., 2019a).

\subsection{Uptake by plants}

A positive correlation was observed between contamination level of soil and plant-uptake of PAEs (Gu et al., 2017). The pathways of absorption are as follows: (1) Plant roots absorb PAEs directly from the soil solution and transfer via the xylem to leaves by transpiration flow, with PAEs accumulating in the edible parts, as was found with corn and soybeans (Chen et al., 2005; Cai et al., 2008b; Sun et al., 2010); (2) aboveground biomass can absorb PAEs directly from the air. With leafy vegetables, such as Chinese cabbage, this can be especially problematic (Zeng et al., 2007). MPs are also understood to be capable of entering into edible biomass. Polystyrene and polymethylmethacrylate particles with submicron and nanometre sizes were able to penetrate the stele at sites of lateral root emergence via 'crack-entry mode' followed by transport to shoots ( $\mathrm{Li}$ et al., 2020). High transpiration rates promoted the uptake of plastic particles, indicating that transpiration pull was the main driving force of their movement (Li et al., 2020). However, we know of no studies on the co-migration of PAEs and MPs from soil to plant biomass. The interactions in flow and transfer of MPs and
PAEs in soil-plant systems are thus still unclear and need to be explored if we are to gain control of these phenomena. PAEs may first adsorb onto MPs which may or may not facilitate entry. In addition, PAEs already present in submicron MPs may escape the MPs and relocate/accumulate with an expected affinity for plant lipids.

\subsection{Degradation of PAEs and MPs}

As the main process of removing POPs, microorganisms play a major role in PAE degradation in the environment under various conditions (Staples et al., 1997). As a new habitat for bacterial growth, MPs could affect the composition of the bacterial community in environmental media (Chi et al., 2021). Laboratory experiments show that the addition of microplastics with a higher affinity for DBP inhibited the degradation of DBP in sediments (Chi et al., 2021). The effect of MPs on the degradation of PAEs may be related to other characteristics, which need further investigation.

Tillage, digging, bioturbation will all increase specific surface area. Old and degraded plastics eventually become fragile and decompose into smaller and smaller microparticles, becoming microplastics. Mechanical erosion of plastic surfaces led to delamination of the surface then produced microplastic particles (Browne et al., 2007; Barnes et al., 2009). As PAEs are not covalently bonded into the polymer structure, the fragmentation of macroplastics may accelerate the release of PAEs and MP/NP-facilitated transport.

\section{Impact of PAEs and MPs on soil ecosystems}

Ecotoxicological studies on PAEs or MPs have focused primarily on the simple deleterious effects of one or the other on plants, fauna, and microorganisms. However, a more accurate description of the consequences of co-pollution requires a multidirectional approach. This includes understanding the factors governing the migration of microplastics and PAEs in biological context: which requires an understanding of biological vectors, especially changes in the behavior of influential soil organisms.

\subsection{Soil macrofauna}

A dose-response relationship between DNA damage in earthworm cells and exposure concentrations of PAEs was studied. With the extension of exposure time, PAEs can cause a decrease in foraging and metabolism, weight loss, swelling, congestion, and even ulceration of earthworms (Wang et al., 2010). The biota-to-soil accumulation factors of DEHP in earthworms (Eisenia fetida) were 0.17 and 0.07 in agricultural and forest soil, respectively (Hu et al., 2005). Earthworm (Prendergast-Miller et al., 2019) burrowing, feeding, and cast behavior (which governs the distribution of many substances 
and associated biota) were found to be significantly affected by ingestion of polyester MP fibers (Prendergast-Miller et al., 2019). Effects such as these will impact upon a range of critical soil properties, with cascading consequences. However, it is not known if the effects were due specifically to the physical MPs themselves or MP-resident PAEs. Other studies of the same model earthworm (Lumbricus terrestris L.) found MP particle-size selectivity for polyester (Lwanga et al., 2016). Soil fauna facilitated the horizontal and vertical transport of MPs in the work of Xu et al. (2020). A simulated experiment confirmed that exposure to high levels of PE MPs $(>28 \%$, not environmentally realistic) inhibited the growth and increased earthworm fatality, while the reproduction rate was unaffected (Zhu et al., 2018). Nonetheless, manual addition of more realistic quantities of low-density polyethylene fragments in the field significantly affected the composition and decreased the abundance of microarthropod and nematode communities (Lin et al., 2020). PAEs and MPs may have synergistic effects causing damage to soil fauna, and the PAE content may be the more influential component explaining the observed impacts of MPs.

\subsection{Soil microorganisms}

The effect of PAEs on microbial community in soils depends on the specific identity and concentration of the PAE. Dimethyl phthalate (DMP) or DEP with the concentrations of $\leqslant 50 \mathrm{mg} \mathrm{kg}^{-1}$ soil showed little effect on the microbial activity, whereas concentrations $\geqslant 100 \mathrm{mg} \mathrm{kg}^{-1}$ soil had statistically significant and deleterious effects (Chen et al., 2013). DOP (Chen et al., 2013) and DEHP (Cartwright et al., 2000) do not exhibit any significant impact on soil microbial activity; even at $100 \mathrm{mg} \mathrm{kg}^{-1}$, DEHP had no effect on membrane fluidity (Cartwright et al., 2000). DBP was found to inhibit the activity, diversity, and heterogeneity of microorganisms in the soil, and also increased microbial utilization of amines and carboxylic acids and decreased the utilization of carbohydrates and amino acids (Gao et al., 2020b).

With the accumulation of MPs in the environment, MPs may gradually affect the bacterial community in environmental media (Julia et al., 2018). MPs in agricultural soils were found to accumulate colonizing microorganisms (Zhang et al., $2019 b$ ), with MPs possibly serving a role in the attraction of hydrophobic C sources (Hirai et al., 2011). Additions of MPs have been found to significantly affect soil microbial respiration and activity of soil b-glucosidase, urease, and phosphatase (Yang et al., 2018). In the study of Gao et al. (2020a), MP addition promoted soil carbon dioxide emissions, and even accelerated succession of the soil bacterial community (Wang et al., 2020a). We infer that PAEs and MPs may have antagonistic effects on the abundance and diversity of a range of microorganisms: except for those responsible for metabolizing organic compounds with an affinity for microplastics. Considering the increasing abundance of MPs and PAEs in soils, these trends may continue.

\subsection{Plants}

The migration of pollutants in soil-plant systems is of paramount importance for food quality, and human health. Accumulation of PAEs in plants affects germination, growth and development as well as interfering with plant metabolismwhich in turn affects pigmentation, osmolytes, stress biomarkers and activities of antioxidative enzymes- thus reducing the edible yield and quality (Kumari and Kaur, 2020). In this instance, DBP accumulation decreased soluble protein content and increasing nitrate content of Brassica napus (Kong et al., 2018), with DBP again emerging more toxic than DEHP (Ma et al., 2018).

Direct toxicity and indirect effects (altering bioturbation, soil structure, nutrient immobilization, transporting or adsorbing contaminants) were considered the main mechanisms for microplastic effects on plants (Rillig et al., 2019). MPs of 100 $\mathrm{nm}$ strongly inhibited seedling establishment and growth of Arabidopsis thaliana (Sun et al., 2020), but the joint toxicity of PAEs and MPs still needs disentangling. In hydroponic systems, the addition of exogenous MPs increased growth inhibition by DBP in lettuce by aggravating photosynthetic activity (Gao et al., 2019). DBP and polystyrene MPs could also disturb microalgal growth. When the concentration of MPs was less than $10 \mathrm{mg} \mathrm{L}^{-1}$, low concentrations of DBP were antagonistic to MPs inhibition of microalgal growth, while a high concentration of DBP enhanced the negative impact of MPs (Li et al., 2020).

Both PAEs and MPs can negatively impact plant growth. The accumulation of MPs in the edible parts of plants increases the risks of human intake of sorbed POPs, and especially PAEs. Risk assessment of PAEs for multiple exposure routes has been established, including inhalation and dermal contact (Wang et al., 2021), and oral intake (Wang et al., 2015). However, the current understanding of the potential impacts on human health associated with an abundance of MPs is limited and insufficient to accurately assess the health risks of consuming them.

\section{Conclusions and perspective}

MPs comprise the crushed debris of various plastic polymers and can both be a source or a sink of PAEs. While 'straight' PAE effects have been widely studied in soils, the interactions with related MP content, soil health, and ecosystem processes need urgent attention. The interactions between PAEs and MPs- including adsorption and degradationaffects both their behavior and persistence in the environment. However, their entwined behavior still lacks sufficiently descriptive data, especially regarding their co-migration and departure from one another. Many challenges remain to be tackled, including the methodologies for extraction and characterization of MPs and PAEs. Specific issues need to be addressed: 1) establishing an efficient, accurate, and 
simple method to quantify different types of microplastics in soils and plants; 2) exploring the behavior and understanding the mechanisms of co-transfer and transformation as interacting with soil biota (especially in vegetable production systems); 3) assessing the risk and consequences of combined and discreet impacts of MPs and PAEs on plants and soil biota, and 4) preventing or reducing the transfer of MPs and PAEs into - and within - the food chain.

\section{Conflict of interest}

The authors declare no competing financial interest.

\section{Acknowledgments}

This research was funded by the National Key Research and Development Program of China (2016YFD0800204), the Outstanding Youth Fund of Natural Science Foundation of Jiangsu, China (BK20150050), the National Natural Science Foundation of China (41977137, 42007145, 41977356), the Key Program of Frontier Sciences, Chinese Academy of Sciences (QYZDJ-SSWDQC035), the Natural Science Foundation of Jiangsu, China (BK20201106). F. Wang was partially supported by the fellowship of Alexander von Humboldt for experienced researchers.

\section{References}

Alvarez-Lopeztello, J., Robles, C., del Castillo, R.F., 2021. Microplastic pollution in neotropical rainforest, savanna, pine plantations, and pasture soils in lowland areas of Oaxaca, Mexico: Preliminary results. Ecological Indicators 121, 107084.

Benson, N.U., Fred-Ahmadu, O.H., 2020. Occurrence and distribution of microplastics-sorbed phthalic acid esters (PAEs) in coastal psammitic sediments of tropical Atlantic Ocean, Gulf of Guinea. Science of the Total Environment 730, 139013.

Cai, Q., Mo, C., Li, Y., Zeng, Q., Wang, B., Xiao, K., Li, H., Xu, G., 2005. The study of PAEs in soils from typical vegetable fields in areas of Guangzhou and Shenzhen, South China. Acta Ecologica Sinica 25, 283-288.

Cai, Q.Y., Mo, C.H., Wu, Q.T., Katsoyiannis, A., Zeng, Q.Y., 2008a. The status of soil contamination by semivolatile organic chemicals (SVOCs) in China: a review. Science of the Total Environment 389, 209-224.

Cai, Q.Y., Mo, C.H., Zeng, Q.Y., Wu, Q.T., Ferard, J.F., AntizarLadislao, B., 2008b. Potential of Ipomoea aquatica cultivars in phytoremediation of soils contaminated with di-n-butyl phthalate. Environmental and Experimental Botany 62, 205-211.

Cartwright, C.D., Thompson, I.P., Burns, R.G., 2000. Degradation and impact of phthalate plasticizers on soil microbial communities. Environmental Toxicology and Chemistry 19, 1253-1261.

Celeiro, M., Dagnac, T., Llompart, M., 2018. Determination of priority and other hazardous substances in football fields of synthetic turf by gas chromatography-mass spectrometry: A health and environmental concern. Chemosphere 195, 201-211.

Chen, H., Zhuang, R., Yao, J., Wang, F., Qian, Y., 2013. A comparative study on the impact of phthalate esters on soil microbial activity. Bulletin of Environmental Contamination and Toxicology 91, 217223.

Chen, R.R., Yin, R., Lin, X.G., Cao, Z.H., 2005. Effect of arbuscular mycorrhizal inoculation on plant growth and phthalic ester degradation in two contaminated soils. Pedosphere 15, 263-269.

Chen, Y., Leng, Y., Liu, X., Wang, J., 2020. Microplastic pollution in vegetable farmlands of suburb Wuhan, central China. Environmental Pollution 257, 113449.

Chen, Y., Luo, Y., Zhang, H., Song, J., 2011. Preliminary study on PAEs pollution of greenhouse soils. Acta Pedologica Sinica 48, 516-523.

Chi, J., Zhang, H., Zhao, D., 2021. Impact of microplastic addition on degradation of dibutyl phthalate in offshore sediments. Marine Pollution Bulletin 162, 111881.

Choi, Y.R., Kim, Y.N., Yoon, J.H., Dickinson, N., Kim, K.H., 2020. Plastic contamination of forest, urban, and agricultural soils: a case study of Yeoju City in the Republic of Korea. Journal of Soils and Sediments 8, 1-12.

Corradini, F., Meza, P., Eguiluz, R., Casado, F., Huerta-Lwanga, E., Geissen, V., 2019. Evidence of microplastic accumulation in agricultural soils from sewage sludge disposal. Science of the Total Environment 671, 411-420.

Dankova, R., Jarosova, A., Polakova, S., 2016. Analysis of Phthalate Presence in Agricultural Soils in the Czech Republic. Polish Journal of Environmental Studies, 25, 443-446.

Ding, L., Wang, X., Ouyang, Z., Chen, Y., Wang, X., Liu, D., Liu, S., Yang, X., Jia, H., Guo, X., 2021. The occurrence of microplastic in Mu Us Sand Land soils in northwest China: Different soil types, vegetation cover and restoration years. Journal of Hazardous Materials 403, 123982.

Ding, L., Zhang, S., Wang, X., Yang, X., Zhang, C., Qi, Y., Guo, X., 2020. The occurrence and distribution characteristics of microplastics in the agricultural soils of Shaanxi Province, in northwestern China. Science of the Total Environment 720, 137525.

Feng, Y., Zhang, Y., Zheng, L., Ying, R., Lin, Y., Wang, G., 2017. Distribution characteristics of phthalic acid esters in soil and vegetables under greenhouse in different areas of Jiangsu Province, China. Journal of Ecology and Rural Environment 33, 308-316.

Francis, R.A., 2018. Artificial lawns: Environmental and societal considerations of an ecological simulacrum. Urban Forestry \& Urban Greening 30, 152-156.

Fred-Ahmadu, O.H., Ayejuyo, O.O., Benson, N.U., 2020. Dataset on microplastics and associated trace metals and phthalate esters in sandy beaches of tropical Atlantic ecosystems, Nigeria. Data in Brief 31, 105755.

Gao, D., Li, X.Y., Liu, H.T., 2020a. Source, occurrence, migration and potential environmental risk of microplastics in sewage sludge and during sludge amendment to soil. Science of the Total Environment 742, 140355.

Gao, M., Dong, Y., Zhang, Z., Song, Z., 2020b. Effect of dibutyl phthalate on microbial function diversity and enzyme activity in wheat rhizosphere and non-rhizosphere soils. Environmental Pollution 265, 114800

Gao, M., Liu, Y., Song, Z., 2019. Effects of polyethylene microplastic 
on the phytotoxicity of di-n-butyl phthalate in lettuce (Lactuca sativa L. var. ramosa Hort). Chemosphere 237, 124482.

Gibson, R., Wang, M.J., Padgett, E., Beck, A.J., 2005. Analysis of 4nonylphenols, phthalates, and polychlorinated biphenyls in soils and biosolids. Chemosphere 61, 1336-1344.

Gu, C., Xiang, L., Ren, W., Wu, W., Liu, C., Fang, G., Wang, F., 2017. Multi- interfacial migration/transformation and effects of phthalic acid esters in soils: A review. Journal of Zhejiang University. Agriculture and Life Sciences 43, 700-712.

Guan, H., Wang, J.S., Wan, H.F., Li, P.X., Yang, G.Y., 2007. PAEs Pollution in soils from typical agriculture area of Leizhou Peninsula. Journal of Agro-Environment Science 26, 622-628 (In Chinese).

Hamilton, A.J., Stagnitti, F., Xiong, X., Kreidl, S.L., Benke, K.K., Maher, P., 2007. Wastewater irrigation: The state of play. Vadose Zone Journal 6, 823-840.

He, D., Luo, Y., Lu, S., Liu, M., Song, Y., Lei, L., 2018. Microplastics in soils: Analytical methods, pollution characteristics and ecological risks. Trends in Analytical Chemistry 109, 163-172.

Hongjun, Y., Wenjun, X., Qing, L., Jingtao, L., Hongwen, Y., Zhaohua, L., 2013. Distribution of phthalate esters in topsoil: a case study in the Yellow River Delta, China. Environmental Monitoring and Assessment 185, 8489-8500.

Hu, X.Y., Wen, B., Shan, X.Q., 2003. Survey of phthalate pollution in arable soils in China. Journal of Environmental Monitoring 5, 649 653.

Hu, X.Y., Wen, B., Zhang, S., Shan, X.Q., 2005. Bioavailability of phthalate congeners to earthworms (Eisenia fetida) in artificially contaminated soils. Ecotoxicology and Environmental Safety 62, 26-34.

Huang, B., Sun, L., Liu, M., Huang, H., He, H., Han, F., Wang, X., Xu, Z., Li, B., Pan, X., 2021. Abundance and distribution characteristics of microplastic in plateau cultivated land of Yunnan Province, China. Environmental Science and Pollution Research International 28, 1675-1688.

Hurley, R.R., Nizzetto, L., 2018. Fate and occurrence of micro(nano) plastics in soils: Knowledge gaps and possible risks. Current Opinion in Environmental Science \& Health 1, 6-11.

Kibblewhite, M.G., Ritz, K., Swift, M.J., 2008. Soil health in agricultural systems. Philosophical Transactions of the Royal Society of London. Series B, Biological Sciences 363, 685-701.

Kitahara, K.I., Nakata, H., 2020. Plastic additives as tracers of microplastic sources in Japanese road dusts. Science of the Total Environment 736, 139694

Kong, S., Ji, Y., Liu, L., Chen, L., Zhao, X., Wang, J., Bai, Z., Sun, Z., 2012. Diversities of phthalate esters in suburban agricultural soils and wasteland soil appeared with urbanization in China. Environmental Pollution 170, 161-168.

Kong, X., Jin, D., Jin, S., Wang, Z., Yin, H., Xu, M., Deng, Y., 2018. Responses of bacterial community to dibutyl phthalate pollution in a soil-vegetable ecosystem. Journal of Hazardous Materials 353, 142-150.

Kumari, A., Kaur, R., 2020. A review on morpho-physiological traits of plants under phthalates stress and insights into their uptake and translocation. Plant Growth Regulation 91, 327-347.

Li, C., Chen, J., Wang, J., Han, P., Luan, Y., Ma, X., Lu, A., 2016a. Phthalate esters in soil, plastic film, and vegetable from green- house vegetable production bases in Beijing, China: Concentrations, sources, and risk assessment. Science of the Total Environment 568, 1037-1043.

Li, K., Ma, D., Wu, J., Chai, C., Shi, Y., 2016b. Distribution of phthalate esters in agricultural soil with plastic film mulching in Shandong Peninsula, East China. Chemosphere 164, 314-321.

Li, L., Luo, Y., Li, R., Zhou, Q., Peijnenburg, W.J.G.M., Yin, N., Yang, J., Tu, C., Zhang, Y., 2020. Effective uptake of submicrometre plastics by crop plants via a crack-entry mode. Nature Sustainability 3, 929-937.

Li, Q., Zeng, A., Jiang, X., Gu, X., 2021. Are microplastics correlated to phthalates in facility agriculture soil? Journal of Hazardous Materials 412, 125164.

Li, Z., Yi, X., Zhou, H., Chi, T., Li, W., Yang, K., 2020. Combined effect of polystyrene microplastics and dibutyl phthalate on the microalgae Chlorella pyrenoidosa. Environmental Pollution 257, 113604.

Lin, D., Yang, G., Dou, P., Qian, S., Zhao, L., Yang, Y., Fanin, N., 1934. 2020. Microplastics negatively affect soil fauna but stimulate microbial activity: insights from a field-based microplastic addition experiment. Proceedings of the Royal Society of London. Series B, Biological Sciences 287, 20201268.

Liu, F.F., Liu, G.Z., Zhu, Z.L., Wang, S.C., Zhao, F.F., 2019. Interactions between microplastics and phthalate esters as affected by microplastics characteristics and solution chemistry. Chemosphere 214, 688-694.

Liu, W.L., Shen, C.F., Zhang, Z., Zhang, C.B., 2009. Distribution of phthalate esters in soil of e-waste recycling sites from Taizhou city in China. Bulletin of Environmental Contamination and Toxicology 82, 665 667.

Liu, Y., Ji, C., Yu, Y., Liu, H., Shen, Y., 2020a. Distribution characteristics and health risk assessment of PAEs in urban soils of Changji City, Xinjiang, China. Global NEST Journal 22, 6774.

Liu, Y., Li, Z., Jalón-Rojas, I., Wang, X.H., Fredj, E., Zhang, D., Feng, L., Li, X., 2020b. Assessing the potential risk and relationship between microplastics and phthalates in surface seawater of a heavily human-impacted metropolitan bay in northern China. Ecotoxicology and Environmental Safety 204, 111067.

Lowman, A., McDonald, M.A., Wing, S., Muhammad, N., 2013. Land application of treated sewage sludge: community health and environmental justice. Environmental Health Perspectives 121, 537-542.

Lv, H., Mo, C.H., Zhao, H.M., Xiang, L., Katsoyiannis, A., Li, Y.W., Cai, Q.Y., Wong, M.H., 2018. Soil contamination and sources of phthalates and its health risk in China: A review. Environmental Research 164, 417-429.

Lv, W., Zhou, W., Lu, S., Huang, W., Yuan, Q., Tian, M., Lv, W., He, D., 2019. Microplastic pollution in rice-fish co-culture system: A report of three farmland stations in Shanghai, China. Science of the Total Environment 652, 1209-1218.

Lwanga, E.H., Gertsen, H., Gooren, H., Peters, P., Salánki, T., van der Ploeg, M., Besseling, E., Koelmans, A.A., Geissen, V., 2016. Microplastics in the Terrestrial Ecosystem: Implications for Lumbricus terrestris (Oligochaeta, Lumbricidae). Environmental Science \& Technology 50, 2685-2691. 
Ma, T., Zhou, W., Chen, L., Li, Y., Luo, Y., Wu, P., 2020. Phthalate esters contamination in vegetable-soil system of facility greenhouses in Jingmen, central China and the assessment of health risk. Environmental Geochemistry and Health 42, 2703-2721.

Ma, T., Zhou, W., Chen, L., Wu, L., Christie, P., Liu, W., 2018. Toxicity of phthalate esters to lettuce (Lactuca sativa) and the soil microbial community under different soil conditions. PLoS One 13, e0208111.

Mo, C.H., Cai, Q.Y., Li, Y.H., Zeng, Q.Y., 2008. Occurrence of priority organic pollutants in the fertilizers, China. Journal of Hazardous Materials 152, 1208-1213.

Niu, L., Xu, Y., Xu, C., Yun, L., Liu, W., 2014. Status of phthalate esters contamination in agricultural soils across China and associated health risks. Environmental Pollution 195, 16-23.

Peijnenburg, W.J., Struijs, J., 2006. Occurrence of phthalate esters in the environment of The Netherlands. Ecotoxicology and Environmental Safety 63, 204-215.

Peng, Y., Zhao, Y., Wang, L., He, Z., Zhang, Y., Geng, Y., Liu, X., 2018. Contamination and risk assessment of phthalates in soils and agricultural products after cotton cultivation in southern Xinjiang, northwest China. Journal of Agro-Environment Science 37, 2678 2686 (In Chinese).

Picó, Y., Alvarez-Ruiz, R., Alfarhan, A.H., El-Sheikh, M.A., Alshahrani, H.O., Barceló, D., 2020. Pharmaceuticals, pesticides, personal care products and microplastics contamination assessment of AlHassa irrigation network (Saudi Arabia) and its shallow lakes. Science of the Total Environment 701, 135021.

Prendergast-Miller, M.T., Katsiamides, A., Abbass, M., Sturzenbaum, S.R., Thorpe, K.L., Hodson, M.E., 2019. Polyester-derived microfibre impacts on the soil-dwelling earthworm Lumbricus terrestris. Environmental Pollution 251, 453-459.

Qi, R., Jones, D.L., Li, Z., Liu, Q., Yan, C., 2020. Behavior of microplastics and plastic film residues in the soil environment: A critical review. Science of the Total Environment 703, 134722.

Rhind, S.M., Kyle, C.E., Ruffie, H., Calmettes, E., Osprey, M., Zhang, Z.L., Hamilton, D., McKenzie, C., 2013. Short- and long-term temporal changes in soil concentrations of selected endocrine disrupting compounds (EDCs) following single or multiple applications of sewage sludge to pastures. Environmental Pollution, 181, 262-270.

Rillig, M.C., Lehmann, A., de Souza Machado, A.A., Yang, G., 2019. Microplastic effects on plants. New Phytologist 223, 1066-1070.

Rios, L.M., Moore, C., Jones, P.R., 2007. Persistent organic pollutants carried by synthetic polymers in the ocean environment. Marine Pollution Bulletin 54, 1230-1237.

Sato, T., Qadir, M., Yamamoto, S., Endo, T., Zahoor, A., 2013. Global regional, and country level need for data on wastewater generation, treatment, and use. Agricultural Water Management 130, 113.

Skrbic, B.D., Ji, Y., Durisic-Mladenovic, N., Zhao, J., 2016. Occurence of the phthalate esters in soil and street dust samples from the Novi Sad city area, Serbia, and the influence on the children's and adults' exposure. Journal of Hazardous Materials 312, 272-279.

Scheurer, M., Bigalke, M., 2018. Microplastics in Swiss floodplain soils. Environmental Science \& Technology 52, 3591-3598.

Škrbić, B.D., Ji, Y., Đurišić-Mladenović, N., Zhao, J., 2016. Occurence of the phthalate esters in soil and street dust samples from the Novi Sad city area, Serbia, and the influence on the children's and adults' exposure. Journal of Hazardous Materials 312, 272-279.

Staples, C.A., Peterson, D.R., Parkerton, T.F., Adams, W.J., 1997. The environmental fate of phthalate esters: A literature review. Chemosphere 35, 667-749.

Sun, T.R., Cang, L., Wang, Q.Y., Zhou, D.M., Cheng, J.M., Xu, H., 2010. Roles of abiotic losses, microbes, plant roots, and root exudates on phytoremediation of PAHs in a barren soil. Journal of Hazardous Materials 176, 919-925.

Sun, X.D., Yuan, X.Z., Jia, Y., Feng, L.J., Zhu, F.P., Dong, S.S., Liu, J., Kong, X., Tian, H., Duan, J.L., Ding, Z., Wang, S.G., Xing, B., 2020. Differentially charged nanoplastics demonstrate distinct accumulation in Arabidopsis thaliana. Nature Nanotechnology 15, 755760.

Takdastan, A., Niari, M.H., Babaei, A., Dobaradaran, S., Jorfi, S., Ahmadi, M., 2021. Occurrence and distribution of microplastic particles and the concentration of Di 2-ethyl hexyl phthalate (DEHP) in microplastics and wastewater in the wastewater treatment plant. Journal of Environmental Management 280, 111851.

Tao, H., Wang, Y., Liang, H., Zhang, X., Liu, X., Li, J., 2020. Pollution characteristics of phthalate acid esters in agricultural soil of Yinchuan, northwest China, and health risk assessment. Environmental Geochemistry and Health 42, 4313-4326.

Vered, G., Kaplan, A., Avisar, D., Shenkar, N., 2019. Using solitary ascidians to assess microplastic and phthalate plasticizers pollution among marine biota: A case study of the Eastern Mediterranean and Red Sea. Marine Pollution Bulletin 138, 618625.

Vikelsøe, J., Thomsen, M., Carlsen, L., 2002. Phthalates and nonylphenols in profiles of differently dressed soils. Science of the Total Environment 296, 105-116.

Vikelsoe, J., Thomsen, M., Carlsen, L. 2002. Phthalates and nonylphenols in profiles of differently dressed soils. Science of the Total Environment 296, 105-116.

Wang, H., Liang, H., Gao, D.W., 2017. Occurrence and risk assessment of phthalate esters (PAEs) in agricultural soils of the Sanjiang Plain, northeast China. Environmental Science and Pollution Research International 24, 19723-19732.

Wang, J., Chen, G., Christie, P., Zhang, M., Luo, Y., Teng, Y., 2015. Occurrence and risk assessment of phthalate esters (PAEs) in vegetables and soils of suburban plastic film greenhouses. Science of the Total Environment 523, 129-137.

Wang, J., Huang, M., Wang, Q., Sun, Y., Zhao, Y., Huang, Y., 2020a. LDPE microplastics significantly alter the temporal turnover of soil microbial communities. Science of the Total Environment 726, 138682.

Wang, L., Liu, M., Tao, W., Zhang, W., Wang, L., Shi, X., Lu, X., Li, X., 2018. Pollution characteristics and health risk assessment of phthalate esters in urban soil in the typical semi-arid city of Xi'an, Northwest China. Chemosphere 191, 467-476.

Wang, X., Chang, L., Sun, Z., Zhang, Y., 2010. Comparative proteomic analysis of differentially expressed proteins in the earthworm Eisenia fetida during Escherichia coli O157:H7 stress. Journal of Proteome Research 9, 6547-6560. 
Wang, Y., Wang, F., Xiang, L., Gu, C., Redmile-Gordon, M., Sheng, H., Wang, Z., Fu, Y., Bian, Y., Jiang, X., 2021. Risk assessment of agricultural plastic films based on release kinetics of phthalate acid esters. Environmental Science \& Technology 55, 3676-3685.

Wang, Z., Meng, Q., Yu, L., Yang, W., Li, W., Yang, J., Yang, F., 2020b. Occurrence characteristics of microplastics in farmland soil of Hetao Irrigation District, Inner Mongolia. Chinese Society of Agricultural Engineering 36, 204-209 (In Chinese).

Weithmann, N., Möller, J.N., Löder, M.G.J., Piehl, S., Laforsch, C., Freitag, R., 2018. Organic fertilizer as a vehicle for the entry of microplastic into the environment. Science Advances 4, eaap8060.

Wu, W., Sheng, H., Gu, C., Song, Y., Willbold, S., Qiao, Y., Liu, G., Zhao, W., Wang, Y., Jiang, X., Wang, F., 2018. Extraneous dissolved organic matter enhanced adsorption of dibutyl phthalate in soils: Insights from kinetics and isotherms. Science of the Total Environment 631-632, 1495-1503.

Xiong, P., Gong, X., Deng, L., 2008. Analysis of PAE pollutants in farm soil and water samples in Nanchang City. Chemistry (Weinheim an der Bergstrasse, Germany) 71, 636-640.

Xu, B., Liu, F., Cryder, Z., Huang, D., Lu, Z., He, Y., Wang, H., Lu, Z., Brookes, P.C., Tang, C., Gan, J., Xu, J., 2020. Microplastics in the soil environment: Occurrence, risks, interactions and fate- $A$ review. Critical Reviews in Environmental Science and Technology 50, 2175-2222.

Yang, G.Y., Zhang, T.B., Gao, S.T., Guo, Z.X., Wan, H.F., Luo, W., Gao, Y.X., 2007. Distribution of phthalic acid esters in agricultural soils in typical regions of Guangdong Province. Journal of Applied Ecology 18, 2308-2312 (In Chinese).

Yang, J., Li, R., Zhou, Q., Li, L., Li, Y., Tu, C., Zhao, X., Xiong, K., Christie, P., Luo, Y., 2021. Abundance and morphology of microplastics in an agricultural soil following long-term repeated application of pig manure. Environmental Pollution 272, 116028.

Yang, X., Bento, C.P.M., Chen, H., Zhang, H., Xue, S., Lwanga, E.H., Zomer, P., Ritsema, C.J., Geissen, V., 2018. Influence of microplastic addition on glyphosate decay and soil microbial activities in Chinese loess soil. Environmental Pollution 242, 338 347.

Yu, L., Zhang, J., Liu, Y., Chen, L., Tao, S., Liu, W., 2021. Distribution characteristics of microplastics in agricultural soils from the largest vegetable production base in China. Science of the Total Environment 756, 143860.

Zeng, F., Lin, Y., Cui, K., Wen, J., Ma, Y., Chen, H., Zhu, F., Ma, Z., Zeng, Z., 2010. Atmospheric deposition of phthalate esters in a subtropical city. Atmospheric Environment 44, 834-840.

Zeng, Q., Mo, C., Q.Y., C, Q.T., Wu, Q.T., 2007. Accumulation features of di(2-ethylhexyl) phthalate in various genotypes of Brassica parachinensis-soil systems. Journal of Agro-Environment Science 26, 2239-2244 (In Chinese).

Zhang, B., Wu, D., Yang, X., Teng, J., Liu, Y., Zhang, C., Zhao, J., Yin, X., You, L., Liu, Y., Wang, Q., 2019a. Microplastic pollution in the surface sediments collected from Sishili Bay, North Yellow Sea, China. Marine Pollution Bulletin 141, 9-15.

Zhang, G.S., Liu, Y.F., 2018. The distribution of microplastics in soil aggregate fractions in southwestern China. Science of the Total Environment 642, 12-20.
Zhang, H., Zhou, Q., Xie, Z., Zhou, Y., Tu, C., Fu, C., Mi, W., Ebinghaus, R., Christie, P., Luo, Y., 2018. Occurrences of organophosphorus esters and phthalates in the microplastics from the coastal beaches in north China. Science of the Total Environment 616-617, 1505-1512.

Zhang, L., Xie, Y., Liu, J., Zhong, S., Qian, Y., Gao, P., 2020. An Overlooked Entry Pathway of Microplastics into Agricultural Soils from Application of Sludge-Based Fertilizers. Environmental Science \& Technology 54, 4248-4255.

Zhang, L., Yang, W., Dong, L., Huang, Y., Shi, S., Zhang, T., Zhou, L., 2011. Pollution characteristics and sources of polycyclic aromatic hydrocarbons and phthalic acid esters in agricultural surface soil from the Southern Jiangsu Province, China. Nongye Huanjing Kexue Xuebao 30, 2202-2209 (In Chinese).

Zhang, M., Zhao, Y., Qin, X., Jia, W., Chai, L., Huang, M., Huang, Y., 2019b. Microplastics from mulching film is a distinct habitat for bacteria in farmland soil. Science of the Total Environment 688, 470-478.

Zhang, M.S., Li, M.Y., Wang, J., Wang, Q., Luo, H., He, Z.Z., He, J., M, C.H., 2009. Occurrence of phthalic acid esters (PAEs) in vegetable fields of Dongguan City. Guangdong Agricultural Sciences 180, 172-175 (In Chinese).

Zhang, S., Liu, X., Hao, X., Wang, J., Zhang, Y., 2020c. Distribution of low-density microplastics in the mollisol farmlands of northeast China. Science of the Total Environment 708, 135091.

Zhang, W., Ma, X., Zhang, Z., Wang, Y., Wang, J., Wang, J., Ma, D., 2015a. Persistent organic pollutants carried on plastic resin pellets from two beaches in China. Marine Pollution Bulletin 99, 28-34.

Zhang, Y., Gao, T., Kang, S., Sillanpää, M., 2019d. Importance of atmospheric transport for microplastics deposited in remote areas. Environmental Pollution 254, 112953.

Zhang, Y., Liang, Q., Gao, R., Hou, H., Tan, W., He, X., Zhang, H., Yu, M., Ma, L., Xi, B., Wang, X., 2015b. Contamination of phthalate esters (PAEs) in typical wastewater-irrigated agricultural soils in Hebei, North China. PLoS One 10, e0137998.

Zhao, X., Zhu, W., Xu, D., Ying, C., Xia, Y., Chu, Y., Yang, X., 2014. Contents and characteristics of phthalic acid esters in municipal sewage sludge in Jiangsu Province. Environmental Engineering 864-867, 861-865.

Zheng, S., Xue, Y., Li, X., Duan, Q., Gao, S., 2016. Phthalate acid esters (PAEs)pollution in soils and agricultural products of vegetable greenhouses in Shouguang City, Shandong Province. Journal of Agro-Environment Science 35, 492-499 (In Chinese).

Zhou, B., Wang, J., Zhang, H., Shi, H., Fei, Y., Huang, S., Tong, Y., Wen, D., Luo, Y., Barceló, D., 2020a. Microplastics in agricultural soils on the coastal plain of Hangzhou Bay, east China: Multiple sources other than plastic mulching film. Journal of Hazardous Materials 388, 121814.

Zhou, Y., Wang, J., Zou, M., Jia, Z., Zhou, S., Li, Y., 2020 b. Microplastics in soils: A review of methods, occurrence, fate, transport, ecological and environmental risks. Science of the Total Environment 748, 141368.

Zhu, D., Chen, Q.L., An, X.L., Yang, X.R., Christie, P., Ke, X., Wu, L.H., Zhu, Y.G., 2018. Exposure of soil collembolans to microplastics perturbs their gut microbiota and alters their isotopic composition. Soil Biology \& Biochemistry 124, 277-278. 